\title{
REGULADORES VEGETAIS NA QUEBRA DA DOMINÂNCIA APICAL DE MAMOEIRO (Carica papaya L.) $)^{1}$
}

\author{
ELIZABETH ORIKA ONO², JOSÉ FRANCISCO GRANA JÚNIOR³, JOÃO DOMINGOS RODRIGUES²
}

\begin{abstract}
RESUMO- O trabalho avaliou os efeitos de reguladores vegetais sobre a quebra da dominância apical de mamoeiro (Carica papaya L. cv. Improved Sunrise Solo). A aplicação dos reguladores vegetais foi iniciada quando as plantas tinham seis meses de idade, totalizando três aplicações, a intervalos de sete dias, constando dos seguintes tratamentos: T1- água (testemunha); T2- GA $250 \mathrm{mg} \mathrm{L}^{-1}$; T3- GA $500 \mathrm{mg} \mathrm{L}^{-1}$; T4- benziladenina (BA) 250 mg $\mathrm{L}^{-1}$; T5- BA $500 \mathrm{mg} \mathrm{L}^{-1}$; T6- GA $125 \mathrm{mg} \mathrm{L}^{-1}+\mathrm{BA} 125 \mathrm{mg} \mathrm{L}^{-1}$; T7- GA $250 \mathrm{mg} \mathrm{L}^{-1}+$ BA $250 \mathrm{mg} \mathrm{L}^{-1}$. Esses tratamentos foram acompanhados da remoção ou não da gema apical. Os resultados mostraram que plantas tratadas com $\mathrm{GA}_{3}+\mathrm{BA}$ a 125 e $250 \mathrm{mg} \mathrm{L}^{-1}$, com e sem a remoção da gema apical, apresentaram maior número de brotações que a testemunha, a qual não apresentou nenhuma brotação das gemas laterais.
\end{abstract}

Termos para indexação: mamão, giberelinas, citocininas, gemas laterais, propagação vegetativa

\section{PLANT GROWTH REGULATORS ON BREAKING APICAL DOMINANCE IN PAPAYA PLANTS (Carica papaya L.)}

ABSTRACT - The objective of this work was to study the effects of gibberelin and cytokinin on breaking apical dominance and axillary buds growth of the Carica papaya L. Papaya plants sprayed three times within a period of 7 days, with the following treatments: T1- water (control), T2- GA 250 mg L-1, T3- GA $500 \mathrm{mg} \mathrm{L}^{-1}$, T4- benzyladenine (BA) $250 \mathrm{mg} \mathrm{L}^{-1}$, T5- BA $500 \mathrm{mg} \mathrm{L}^{-1}$, T6- GA $125 \mathrm{mg} \mathrm{L}^{-1}+\mathrm{BA}_{12} 25 \mathrm{mg} \mathrm{L}^{-1}, \mathrm{~T}^{-}-\mathrm{GA}_{3} 250 \mathrm{mg} \mathrm{L}^{-1}+\mathrm{BA}^{2} 250$ $\mathrm{mg} \mathrm{L}^{-1}$. The treatments were carried out with or without removal of the apical buds. After 36 days of the last plant growth regulators application was observed lateral bud numbers, lateral buds length and lateral buds diameter. The results showed that there were a higher number of shoots in plants treated with $\mathrm{GA}_{3}$ at $125 \mathrm{mg} \mathrm{L}^{-1}+\mathrm{BA}$ at $125 \mathrm{mg} \mathrm{L}^{-1}$ and $\mathrm{GA}_{3}$ at $250 \mathrm{mg} \mathrm{L}^{-1}+\mathrm{BA}$ at $250 \mathrm{mg} \mathrm{L}^{-1}$. The removal of the apical bud helped the sprouting of the papaya plants.

Index terms: papaya, gibberellins, cytokinin, axillary buds, vegetative propagation

O mamoeiro (Carica papaya L.) é uma fruteira típica de regiões tropicais e subtropicais. O mesmo é conhecido por: papaia, no México; fruta boma, em Cuba; passaraiva, no Nordeste do Brasil. O Brasil destacase como o País que mais produz mamão em escala internacional, concentrando $29 \%$ da oferta mundial, seguido da Índia com $24 \%$, Tailândia com $8,8 \%$, México com 7,4\% e Indonésia com 5,9\%. No Brasil, mesmo sendo cultivado em praticamente todo o território nacional, à exceção de algumas regiões com invernos rigorosos, as regiões Sudeste e Nordeste somam em média 87,5\% da produção nacional, destacandose os Estados do Espírito Santo e Bahia como os principais produtores destas regiões. O desenvolvimento de plantas de mamão transgênico (receberam um gene a mais) resistentes ao vírus, a partir de técnicas de engenharia genética e da biologia molecular, possibilitará que o cultivo do mamoeiro deixe o nomadismo, reintroduzindo-o em áreas abandonadas, além de proporcionar a melhoria da produtividade, da qualidade e do aspecto do fruto e, consequientemente, maior competitividade do mamão brasileiro no mercado internacional. (Fonte: http://www.fortunecity.com/greenfield/deercreek/741/cultura.html)

A propagação do mamoeiro pode ser realizada através de sementes, porém induz à ocorrência de variações genéticas indesejáveis devido à polinização aberta, resultando na mistura de genótipos. Além de problemas na germinação, pela ocorrência de substâncias inibidoras presente no arilo, a extração e a conservação das sementes ainda precisam ser melhor estudadas, uma vez que as sementes podem perder o poder germinativo em períodos relativamente curtos (Couto, 1983).

Neste sentido, a utilização de um método de propagação vegetativa para a obtenção de mudas, por meio de estaquia, seria muito conveniente. Segundo Hartmann et al. (2002), a propagação por estaquia é um dos métodos mais importantes e utilizados na horticultura para a regeneração clonal. As razões para a utilização da propagação vegetativa são: fixação de genótipos selecionados, uniformidade de populações, facilidade de propagação, antecipação do período de florescimento, combinação de mais de um genótipo numa planta-matriz e maior controle das fases de desenvolvimento (Zuffellato-Ribas \& Rodrigues, 2001).

De acordo com São José \& Marin (1988), a propagação vegetativa é uma forma de multiplicar plantas mantendo-se as características das plantas-mãe. No entanto, para a cultura do mamoeiro, a propagação vegetativa em escala comercial não é usual, devido à dificuldade de retirada de material para essa metodologia, pois o mamoeiro apresenta pouca brotação lateral. Esse fato deve-se à dominância apical que ocorre em conseqüência da presença de auxina na zona meristemática, limitando o desenvolvimento dos meristemas laterais (Taiz $\&$ Zeiger, 2004).

A dominância apical e sua quebra podem ser divididas em 4 fases: (I) formação da gema lateral; (II) imposição da inibição do crescimento da gema lateral; (III) quebra da dominância apical após a decapitação, e (IV) desenvolvimento da gema (Cline, 1997). Logo após a decapitação (fase III), tem-se o início do crescimento das gemas laterais, o qual pode também ser promovido com citocininas sintéticas e inibido com auxinas sintéticas na região decapitada. A fase IV, fase de desenvolvimento das gemas laterais, pode ser promovida pela aplicação de giberelina (Cline, 1997).

A maior concentração de IAA (ácido indolil-3-acético) na gema apical inibe o desenvolvimento das gemas laterais (Taiz \& Zeiger, 2002), por atuar como um dreno de nutrientes e citocininas para a gema apical. Além disso, o elevado nível de auxina nas gemas apicais auxilia na manutenção de altos níveis de ABA (ácido abscísico) nas gemas laterais, inibindo o crescimento dessas (Taiz \& Zeiger, 2002). Dessa forma, a remoção da gema apical promoveria o aumento de citocininas nas gemas laterais, promovendo o desenvolvimento destas.

Estudos têm mostrado o efeito do $\mathrm{GA}_{3}$ exógeno sobre o desenvolvimento vegetal. Os estudos mostram que o $\mathrm{GA}_{3}$ apresenta papel fundamental na regulação do crescimento das brotações, aumentando o comprimento dos internós (Takahashi et al., 1991). Segundo os mesmos autores, a mistura de $\mathrm{GA}_{4+7}$ (ácido giberélico 4 + 7) também tem mostrado ser ativa no crescimento das brotações.

A avaliação do número de gemas desenvolvidas em plantas submetidas a tratamentos com reguladores vegetais tem sido relatada na literatura. Allan \& Mac Millan (1991) utilizaram citocinina, benziladenina (BA) e GA aplicados no caule das plantas de mamoeiro, seguido da retirada da gema apical e obtiveram grande número de brotações laterais. Allan et al. (1993) associaram citocininas sintéticas a

\footnotetext{
${ }^{1}$ (Trabalho 144/2003). Recebido: 03/10/2003. Aceito para publicação: 29/07/2004

2 Prof. ( $\left.{ }^{a}\right)$ Dr. ( $\left.{ }^{a}\right)$, Dept ${ }^{\circ}$ de Botânica, IB - UNESP, C.P. 510, CEP 18618-000, Botucatu, SP. mingo@ibb.unesp.br; eoono@ibb.unesp.br

${ }^{3}$ Mestre em Agronomia, Pós-graduando em Agronomia, Dept ${ }^{\circ}$ de Horticultura, FCA, Campus de Botucatu - UNESP, Botucatu, SP. jfg@netsite.com.br
} 
$\mathrm{GA}_{3}$ e $\mathrm{GA}_{4+7}$ e observaram crescimento significativo das gemas laterais. Costa \& Costa (1996) também aplicaram $\mathrm{GA}_{3}$ associado a citocininas e obtiveram indução da brotação.

Para Norton \& Norton (1986), o tratamento de plantas de mamoeiro com citocinina associada com uma giberelina tem sido eficiente para induzir a formação de ramos laterais a partir de gemas axilares dormentes de plantas adultas, promovendo também seu alongamento e desenvolvimento.

Assim, o objetivo do presente trabalho foi verificar o efeito da aplicação de citocininas e giberelinas com a remoção ou não das gemas apicais sobre o desenvolvimento de gemas laterais em plantas de mamão (Carica papaya L.).

As mudas de mamoeiro (Carica papaya L. cv. Improved Sunrise Solo) foram plantadas na Fazenda São Marcelo localizada no município de Jaú-SP, sendo o clima da região do tipo subtropical com verão chuvoso e inverno seco e o solo classificado como Latossolo Roxo.

O solo do local foi preparado seguindo as recomendações para o plantio da cultura e adubado de acordo com o resultado da análise química do solo. Foram utilizados $500 \mathrm{~g}$ de termofosfato, $100 \mathrm{~g}$ de superfosfato simples, $50 \mathrm{~g}$ de cloreto de potássio e 5 litros de esterco de curral por cova. Foi realizada, também, adubação de cobertura constituída de 3 aplicações de $60 \mathrm{~g}$ de uréia e $20 \mathrm{~g}$ de $\mathrm{KCl}$ por cova, sendo $1 / 3$ um mês após o plantio e o restante nos dois meses subseqüentes. O espaçamento entre plantas foi de 2,0 m e entre as filas duplas de 4,0 m. Cada parcela foi constituída de seis plantas, equivalente a uma população de 2.000 plantas por hectare.

A aplicação dos reguladores vegetais, via aplicação foliar, foi iniciada quando as plantas estavam com seis meses de idade, via aplicação foliar, sendo realizada no período da manhã, das 7 às 10 h. No total, foram realizadas três aplicações em intervalos semanais, sendo a primeira no dia 26-01, a segunda no dia 02-02 e a terceira no dia 09-02. Os tratamentos com os reguladores vegetais foram associados à remoção ou não da gema apical. Desta forma, delinearam-se os seguintes tratamentos: 1- água (testemunha); 2- GA (ácido giberélico 3) $250 \mathrm{mg} \mathrm{L}$ ;; 3- $\mathrm{GA}_{3} 500 \mathrm{mg} \mathrm{L}^{-1}$; 4- BA (benziladenina) $250 \mathrm{mg} \mathrm{L}^{-1}$; 5- BA $500 \mathrm{mg} \mathrm{L}^{-1}$; 6- $\mathrm{GA}_{3} 125 \mathrm{mg} \mathrm{L}^{-1}+\mathrm{BA} 125 \mathrm{mg} \mathrm{L}^{-1}$; 7- GA $250 \mathrm{mg} \mathrm{L}^{-1}+\mathrm{BA} 250 \mathrm{mg} \mathrm{L}^{-1}$.

Após 36 dias da última aplicação, foram verificados os seguintes parâmetros: número de brotações laterais, comprimento e diâmetro das brotações laterais desenvolvidas (em mm).

O delineamento experimental utilizado foi o de blocos casualizados, com 14 tratamentos e quatro repetições. Os dados obtidos foram submetidos à análise de variância (teste $\mathrm{F}$ ), em esquema fatorial 2 x 7 (remoção ou não das gemas apicais e sete tratamentos). As médias foram comparadas pelo teste Tukey, a 5\% de probabilidade.

Através da análise de variância, verificou-se o efeito significativo dos reguladores vegetais, da remoção ou não das gemas apicais e da interação entre os reguladores vegetais e a remoção ou não das gemas sobre o número de brotações laterais desenvolvidas. $\mathrm{Na}$ comparação das médias pelo teste Tukey (Tabela 1), verifica-se que tratamentos com a mistura de $\mathrm{GA}_{3}$ e citocinina (BA) promoveram maior desenvolvimento das brotações ( $\mathrm{GA}_{3}$ a $125 \mathrm{mg} \mathrm{L}^{-1}+\mathrm{BA}$ a $125 \mathrm{mg} \mathrm{L}^{-1} \mathrm{e}$ $\mathrm{GA}_{3}$ a $250 \mathrm{mg} \mathrm{L}^{-1}+\mathrm{BA}$ a $250 \mathrm{mg} \mathrm{L}^{-1}$ ), com e sem a retirada da gema apical. Assim, com a utilização desses tratamentos, a retirada da gema apical torna-se desnecessária, uma vez que os resultados obtidos foram semelhantes. No tratamento dos mamoeiros com $\mathrm{GA}_{3}$ ou BA isolados, o número de brotações desenvolvidas foi reduzido, principalmente com BA a $250 \mathrm{mg} \mathrm{L}^{-1}$ sem a retirada da gema apical, podendo-se sugerir que a concentração de BA (citocinina) tenha sido insuficiente para promover a quebra da dominância apical.

A dominância apical é determinada pela auxina, mas estudos fisiológicos mostram que a citocinina está fortemente ligada com o início do crescimento das gemas laterais; assim, a aplicação de citocinina estimula a divisão celular e o crescimento das gemas em muitas espécies (Taiz \& Zeiger, 2004). No caso do mamoeiro, a citocinina utilizada isoladamente, com e sem a retirada da gema apical, não promoveu o maior desenvolvimento das brotações laterais, quando comparadas com
TABELA 1- Número médio de brotações desenvolvidas em mamoeiro (Carica papaya L.), tratado com reguladores vegetais e água, com a remoção ou não da gema apical.

\begin{tabular}{lcc}
\hline Tratamentos & $\begin{array}{c}\mathrm{C} / \text { retirada da gema } \\
\text { apical }\end{array}$ & $\begin{array}{c}\mathrm{S} / \text { retirada da gema } \\
\text { apical }\end{array}$ \\
\hline Água & 0,00 & 0,00 \\
$\mathrm{GA}_{3}$ 250mg. $\mathrm{L}^{-1}$ & $42,25 \mathrm{Ab}$ & $32,75 \mathrm{Bbc}$ \\
$\mathrm{GA}_{3}$ 500mg. L & $47,25 \mathrm{Ab}$ & $39,00 \mathrm{Bb}$ \\
$\mathrm{BA} 250 \mathrm{mg} . \mathrm{L}^{-1}$ & $22,50 \mathrm{Ac}$ & $4,50 \mathrm{Bd}$ \\
$\mathrm{BA} 500 \mathrm{mg} \cdot \mathrm{L}^{-1}$ & $39,50 \mathrm{Ab}$ & $28,25 \mathrm{Bc}$ \\
$\mathrm{GA}_{3}+\mathrm{BA}$ a $125 \mathrm{mg} . \mathrm{L}^{-1}$ & $59,50 \mathrm{Aa}$ & $58,75 \mathrm{Aa}$ \\
$\mathrm{GA}_{3}+\mathrm{BA}$ a 250mg. L & $59,75 \mathrm{Aa}$ & $60,00 \mathrm{Aa}$ \\
\hline
\end{tabular}

Médias seguidas de mesma letra, maiúscula nas linhas e minúsculas nas colunas, não diferem significativamente entre si, pelo teste Tukey, a 5\% de probabilidade.

os tratamentos com GA isolado ou em mistura com BA. Lang (1996), em cerejeira, relata que a dormência das gemas pode ser quebrada tanto pela aplicação de citocininas como de giberelinas.

Observou-se no experimento que as plantas tratadas com água não apresentaram brotação, mesmo naquelas que tiveram as gemas apicais retiradas no período de avaliação do experimento, sugerindo-se que o mamoeiro seja uma planta de difícil formação de brotações laterais.

Segundo Taiz \& Zeiger (2004), após a decapitação, os níveis de auxina nas gemas laterais aumenta, os níveis de ABA diminuem e o transporte de nutrientes e citocininas das raízes para a gema lateral aumenta. A ação primária da citocinina no crescimento da gema parece estar envolvida no estímulo da divisão celular, distribuição de $\mathrm{Ca}^{2+}$, mudanças na extensibilidade da parede celular e síntese de proteínas (Musgrave, 1994). Como já citado, Cline (1997) afirma que a quebra da dominância apical possa ser promovida com citocininas sintéticas, e o crescimento das gemas laterais pode ser promovido pela aplicação de giberelina.

Em função desses efeitos fisiológicos das citocininas e das giberelinas é que o tratamento das plantas de mamoeiro com $\mathrm{GA}_{3}+\mathrm{BA}$ respondeu com maior número de brotações desenvolvidas que os demais tratamentos.

Através da análise de variância, verificou-se que houve efeito significativo dos reguladores vegetais, da remoção ou não das gemas apicais $(27,80)$ e da interação entre os reguladores vegetais e a remoção ou não das gemas $(2,69)$ sobre o diâmetro das brotações desenvolvidas. No geral, plantas que tiveram a sua gema apical removida, apresentaram brotações com maior diâmetro. A citocinina sintética, aplicada isoladamente (BA), promoveu maior crescimento em diâmetro que o $\mathrm{GA}_{3}$, porém a aplicação desses dois reguladores vegetais conjuntamente proporcionou maior crescimento em diâmetro, principalmente o tratamento com $\mathrm{GA}_{3}$ a $250 \mathrm{mg} \mathrm{L}^{-1}+\mathrm{BA}$ a $250 \mathrm{mg} \mathrm{L}^{-1} \mathrm{e}$ a retirada da gema apical (Tabela 2).

Através da análise de variância, verificou-se que houve efeito significativo dos reguladores vegetais, da remoção ou não das gemas apicais e da interação entre os reguladores vegetais e a remoção ou não das gemas sobre o comprimento das brotações desenvolvidas. Plantas de mamoeiro que foram tratadas com $\mathrm{GA}_{3}$, apresentaram brotações mais longas que plantas tratadas apenas com BA. A citocinina sintética, aplicada isoladamente, promoveu reduzido crescimento em comprimento das brotações desenvolvidas. Mas a mistura desses dois reguladores vegetais proporcionou maior crescimento em comprimento das brotações, principalmente o tratamento com $\mathrm{GA}_{3}$ a $250 \mathrm{mg} \mathrm{L}^{-1}+\mathrm{BA}$ a $250 \mathrm{mgL}^{-1}$ e a retirada da gema apical (Tabela 2).

Os resultados obtidos neste trabalho indicam claramente a influência do $\mathrm{GA}_{3}$ e da citocinina sintética (BA) no processo de desenvolvimento celular, conforme já demonstraram diversos autores (Allan, 1967; Modesto \& Siqueira, 1981; Allan \& Mac Millan, 1991). O efeito mais notável das giberelinas é promover o alongamento celular, mas, também, promovem a divisão celular, atuando tanto em folhas como em caules (Modesto \& Siqueira, 1981). Segundo Taiz \& Zeiger (2004), um dos efeitos das giberelinas é estimular o alongamento e a divisão 
TABELA 2- Diâmetro e comprimento médio ( $\mathrm{mm}$ ) de brotações desenvolvidas em mamoeiro (Carica papaya L.), tratado com fitorreguladores e água, com a remoção ou não da gema apical.

\begin{tabular}{|c|c|c|c|c|}
\hline Tratamentos & Com reti & gema apical & Sem ret & gema apical \\
\hline & Diâmetro (mm) & Comprimento (mm) & Diâmetro (mm) & Comprimento (mm) \\
\hline Água & 0,00 & 0,00 & 0,00 & 0,00 \\
\hline $\mathrm{GA}_{3} 250 \mathrm{mg} . \mathrm{L}^{-1}$ & $5,47 \mathrm{Ac}$ & $101,83 \mathrm{Ac}$ & 4,09 Bd & $54,36 \mathrm{Bc}$ \\
\hline $\mathrm{GA}_{3} 500 \mathrm{mg} \cdot \mathrm{L}^{-1}$ & $5,00 \mathrm{Ac}$ & $111,85 \mathrm{Abc}$ & 4,85 Acd & $97,04 \mathrm{Ab}$ \\
\hline BA $250 \mathrm{mg} . \mathrm{L}^{-1}$ & $6,61 \mathrm{Ab}$ & $20,92 \mathrm{Ad}$ & $5,69 \mathrm{Bbc}$ & $16,43 \mathrm{Ad}$ \\
\hline BA $500 \mathrm{mg} . \mathrm{L}^{-1}$ & $6,72 \mathrm{Ab}$ & $22,01 \mathrm{Ad}$ & $6,54 \mathrm{Aab}$ & $21,42 \mathrm{Ad}$ \\
\hline $\mathrm{GA}_{3}+\mathrm{BA}$ a $125 \mathrm{mg} . \mathrm{L}^{-1}$ & 7,36 Aab & $133,33 \mathrm{Ab}$ & $6,30 \mathrm{Bab}$ & $100,66 \mathrm{Bb}$ \\
\hline $\mathrm{GA}_{3}+\mathrm{BA}$ a $250 \mathrm{mg} \cdot \mathrm{L}^{-1}$ & $8,25 \mathrm{Aa}$ & $193,86 \mathrm{Aa}$ & $7,05 \mathrm{Ba}$ & $133,83 \mathrm{Ba}$ \\
\hline
\end{tabular}

Médias seguidas de mesma letra, maiúscula nas linhas e minúsculas nas colunas, não diferem significativamente entre si, pelo teste Tukey, a 5\% de probabilidade.

celular, promovendo o crescimento tanto pelo aumento do tamanho das células como pelo número de células.

A retirada da gema apical parece ter sido mais benéfica, tanto no crescimento em diâmetro como no crescimento em comprimento das gemas laterais desenvolvidas do que na indução da formação das brotações laterais, provavelmente por aumentar a disponibilidade de nutrientes e citocininas às gemas laterais.

Observando-se os resultados obtidos para diâmetro e comprimento das brotações (Tabela 2), sugere-se que a giberelina parece ter sido imprescindível para promover o crescimento em comprimento através da sua atividade sobre o alongamento celular e a citocinina no crescimento em diâmetro pela sua atividade na promoção da divisão celular.

Através dos resultados obtidos, pode-se concluir que:

A remoção da gema apical não induziu maior formação das brotações laterais, mas promoveu o crescimento em diâmetro e comprimento. O tratamento das plantas com GA $125 \mathrm{mg} \mathrm{L}^{-1}+\mathrm{BA} 125 \mathrm{mg}$ $\mathrm{L}^{-1} \mathrm{e} \mathrm{GA}_{3} 250 \mathrm{mg} \mathrm{L}^{-1}+\mathrm{BA} 250 \mathrm{mg} \mathrm{L}^{-1}$ promoveu o desenvolvimento das brotações laterais e o posterior crescimento destas.

\section{REFERÊNCIAS BIBLIOGRÁFICAS}

ALLAN, P. Production from cuttings. Farming South African, Pretoria, v.42, p.15-21, 1967.

ALLAN, P.; Mac MILLAN, C.N. Advances in propagation of Carica papaya L. cv. Honey Gold cuttings. Journal of the South African Horticulture Science, Stellenbosch, v.1, n.2, p.69-72, 1991.

ALLAN, P.; TAYLER, S.; ALLWOOD, M. Lateral bud induction and effects of fungicides on leaf retention and rooting of Honey Gold papaws. Journal of the South African Horticulture Science,
Stellenbosch, v.3, p.5-8, 1993.

CLINE, M.G. Concepts and terminology of apical dominance. American Journal of Botany, Ithaca, v.84, n.9, p.1064-1069, 1997.

COSTA, A.F.S.; COSTA, A.N. Propagação vegetativa do mamoeiro. In: CONGRESSOBRASILEIRODEFRUTICULTURA, 14., 1996, Curitiba. Resumos... Curitiba: Sociedade Brasileira de Fruticultura, 1996. p.289. COUTO, F.A.D.A. Produção de mudas de mamoeiro e maracujazeiro. Informe Agropecuário, Petrolina, v.9, n.102, p.15-18, 1983.

HARTMANN, H.T.; KESTER, D.E.; DAVIES JR, F.T.; GENEVE, R.L. Plant propagation: principles and practices. 7.ed. New Jersey: Prentice-Hall, 2002. 880p.

MODESTO,Z.M.; SIQUEIRA, M.J.B. Botânica. São Paulo: E.P.U., 1981. $341 \mathrm{p}$.

MUSGRAVE, M.E. Cytokinins and oxidative process. In: MOK, D.W.S.; MOK, M.C. Cytokinin: chemistry, activity, and function. Boca Raton: CRC Press, 1994. p.167-178.

NORTON, M.E.; NORTON, C.R. An alternative to in vitro propagation axillary shoot enhacement on whole plants. Journal of Horticultural Science, Ashford, v.61, p.423-427, 1986.

SÃO JOSÉ, A.R.; MARIN, S.L.D. Propagação do mamoeiro. In: RUGGIERO, C. Mamão. Jaboticabal: FUNEP, 1988. p.177-196.

TAIZ, L.; ZEIGER, E. Plant physiology. 3.ed. Sunderland: Sinauer Associates, 2002. p.423-460.

TAIZ, L.; ZEIGER, E. Fisiologia vegetal. Porto Alegre: Artmed, 2004. p.449-484.

TAKAHASHI, N.; PHINNEY, B.O.; MAC MILLAN, J. Gibberellins. New York: Springer-Verlag, 1991. p.199-210.

ZUFFELLATO-RIBAS, K.C.; RODRIGUES, J.D. Estaquia: uma abordagem dos principais aspectos fisiológicos. Curitiba: Imprensa Universitária da UFPR, 2001. 39p. 